\title{
Land Use Transitions under Rapid Urbanization in Chengdu-Chongqing Region: A Perspective of Coupling Water and Land Resources
}

\author{
Yuchen Pan ${ }^{1}$, Li Ma ${ }^{1}$ *, Hong Tang ${ }^{2}$, Yiwen $\mathrm{Wu}^{1}$ and Zhongjian Yang ${ }^{2}$ \\ 1 School of Public Affairs, Chongqing University, Chongqing 400044, China; 20183258@cqu.edu.cn (Y.P.); \\ 20182887@cqu.edu.cn (Y.W.) \\ 2 Sichuan Center for Rural Development Research, College of Management, Sichuan Agricultural University, \\ Chengdu 611130, China; tanghong@sicau.edu.cn (H.T.); yangzj.19@scu.edu.cn (Z.Y.) \\ * Correspondence: mal.1991@cqu.edu.cn
}

check for

updates

Citation: Pan, Y.; Ma, L.; Tang, H.; Wu, Y.; Yang, Z. Land Use Transitions under Rapid Urbanization in Chengdu-Chongqing Region: A Perspective of Coupling Water and Land Resources. Land 2021, 10, 812. https: / / doi.org/10.3390/ land10080812

Academic Editors: Zahra Kalantari and Dietrich Schmidt-Vogt

Received: 30 June 2021

Accepted: 27 July 2021

Published: 2 August 2021

Publisher's Note: MDPI stays neutral with regard to jurisdictional claims in published maps and institutional affiliations.

Copyright: (c) 2021 by the authors. Licensee MDPI, Basel, Switzerland. This article is an open access article distributed under the terms and conditions of the Creative Commons Attribution (CC BY) license (https:// creativecommons.org/licenses/by/ $4.0 /)$.

\begin{abstract}
Land resources and water resources are the important material basis of economic and social development, and their pattern determines the pattern of development. Based on the panel data of the Chengdu-Chongqing Economic Circle from 2011 to 2018, this paper evaluates the matching degree of water and land resources, and their respective matching degrees with the economic development in the Chengdu-Chongqing Economic Circle with the Gini coefficient method. Based on the two-way fixed effect model, an extended Cobb-Douglas production function model is established to analyze the sensitivity of economic growth to land and water factors. In addition, the restriction degree of water and land resources to the economic development of the Chengdu-Chongqing Economic Circle is measured quantitatively by using the growth damping coefficient. The results show that the water and land resources and economic development of the Chengdu-Chongqing Economic Circle have a high matching degree, but the inner cities have a great difference. The contribution of water resources to economic growth is greater than that of land resources. Both of them have a little growth drag, which shows that industrial development has disposed of the dependence of water and land resources. The development of the Chengdu-Chongqing Economic Circle needs to play the role of technological progress in promoting economic growth, and at the same time optimize the use of water and land resources to reduce its constraints on the economic growth. Finally, the policy suggestions of matching water and land resources and economic growth in different regions are put forward.
\end{abstract}

Keywords: water and land resources management; sustainable development; economic impacts; land use transitions; Chengdu-Chongqing economic circle

\section{Introduction}

Natural resources are a key factor in the economic development of all countries, of which water and land resources are the most basic natural resources. Daly points out that land is a key factor in all aspects of production [1]. The area, quality and development degree of land resources determine the production efficiency, which is the basis of human survival and economic activities. The endowment of water resources and the rationality of their development and utilization influence the utilization of other resources to a great extent [2,3]. Therefore, the abundance of water and land resources not only determines the regional ecological environment quality and population carrying capacity, but also affects the speed of the regional economic growth. The Heckscher-Ohlin theory and the bulk product theory also believe that the use of resource advantages can effectively promote regional economic development. However, with the continuous growth of the population, the shortage of water resources has become an important factor restricting the sustainable development of the environment and society [4]. The conflict between 
limited water resources and the rising water demand highlights the need for a rational and effective water allocation [5]. Large amounts of water and land have long been exploited for fuel, rapid economic growth and an increasing demand has intensified water and soil loss, posing huge risks to the economy [6-8].

China's land resources are seriously wasted. According to the Ministry of Land and Resources of the People's Republic of China, about 32 million acres of arable land are used for new construction each year, but much of that is wasted due to a lack of proper planning and use [9]. At the same time, China also faces the contradiction between the serious shortage of water resources and the rapid economic development. China is short of 50 billion cubic meters of water each year, ranking as one of the 13 countries with the worst water shortage by the United Nations [10]. On the other hand, the exploitation of water resources also poses a severe challenge to the sustainable development of the economy and society [11]. If the necessary industrial structure adjustment and effective engineering and non-engineering measures are not taken, the potential of water resources development and utilization will become smaller and smaller, and may even result in negative growth [12]. To make matters worse, the spatial and temporal distribution of water resources in China is highly uneven [4]. For example, the Yangtze River basin and its southern region hold only $37 \%$ of the land but $81 \%$ of China's water resources [13]. Urbanization and industrialization have led to a reduction in arable land and an increase in the imbalance between water supply and demand, with an even greater reduction in arable land and labor [14]. The contradiction between water and land resources and economic development intensifies, which restricts economic development. It is urgent to evaluate and grasp the matching condition of water and land resources and optimize the allocation and utilization of limited water and land resources. However, how can this constraint be measured quantitatively? How can the matching degree between water and land resources and economy be revealed, and how can the interactive mechanism between water and land resources and economic development be explored? Therefore, it is of great strategic significance to formulate macro-level optimal control policies and measures of water and land resources for ensuring a sustainable utilization of resources and promoting regional coordinated development.

As an important growth pole of the western development, the Chengdu-Chongqing region has an important strategic position in the national and regional development. The natural resources in this area are well endowed, but the level of urban economic development is not balanced, and many cities are relatively backward. Owing to the characteristics of the Chengdu-Chongqing area, it is typical and representative to explore the matching degree between water and land resources and economic development. Based on the above understanding, the objectives of this paper are to:

(1) Reveal the matching degree of water and land resources and economic development in the Chengdu-Chongqing Economic Circle.

(2) Probe into the reason of regional difference of different economic growth in the Chengdu-Chongqing Economic Circle.

(3) Put forward a policy suggestion of optimizing the allocation of water and land resources and promoting the development of the regional economy.

The study not only enriches the theoretical research on the relationship between water and land resources and economic development, but also provides scientific decision support for the coordinated development of the regional economy and the utilization of water and land resources.

\section{Literature Review}

Throughout the relevant research, we can see that the role of water and land resources in economic development has long attracted scholars' attention. Current research on the relationship between water resources and regional economic development mainly focuses on water resources allocation and economic output [15-18], using water resources utilization indexes such as degree and efficiency to describe the relationship between 
the level of water resources utilization and the level of economic development. Davies and Simonovic proposed the integration of global water resources and social-economicenvironmental systems [19]. Qi et al. proposed a comprehensive indicator of the social and economic consumption level of water resources, and determined the red line of regional water resources utilization through the description of the pressure of water resources utilization [12]. Generally speaking, if there is no external influence, the total amount of water resources in an area is basically stable, and the total water consumption in the area will increase with economic development [20]. Therefore, it is urgent to promote water resource utilization by coordinating relevant factors and optimizing the allocation of limited agricultural water resources [5].

The land is a key factor in production in all aspects, and is the basis of human survival and economic activities [1]. Among all types of land, arable land plays a vital role. Ji et al. adopted the Nested IOA method to deal with the allocation of direct and embodied arable land of an urban economy under the background of economic globalization [21]. In addition, construction land has also made an important contribution to promoting social and economic growth [22-24]. Many existing theoretical and practical studies have shown that there is a significant interaction between the economy and changes in construction land [25-27]. Some scholars have conducted a detailed analysis of the dynamic relationship between economy and construction land. For example, a study on the relationship between urban construction land expansion and economic growth in the Yangtze River Economic Belt shows that urban construction land expansion in the Yangtze River Economic Belt has a significant impact on economic growth [28]. However, the inefficient use of construction land is also common [29].

The matching of water and land resources with socio-economic factors is the goal of the rational allocation of water and land resources. Many scholars have conducted a series of studies on the matching degree of water and land resources with socio-economic factors. Saway et al. used remote sensing and other methods to analyze the potential of local land and water resources [30]. Based on the coupling degree model and the water and land resource matching model, some scholars have analyzed the coupling effect between economic development and water and land resources development and the characteristics of temporal and spatial differentiation [31-33]. With the development of the economy and the scarcity of natural resources, scholars have begun to pay attention to the constraints of natural resources on the economy and the extent to which the development of land and space is restricted by water and land resources. Nordhaus et al. incorporated natural resources, including land, into the Solow model, and established two neoclassical economic growth models with and without resource constraints [34]. Based on the difference in the growth rate of output per capita between the two under steady-state conditions, Nordhaus innovatively proposed the concept of "growth drag" and used this model to examine the impact of resources and land on the US economy. Bruvoll et al. pointed out that the constraints of the natural environment will lead to the social cost of environmental governance, and used the dynamic resource environment application model to calculate and predict the degree of welfare loss caused by the environmental tail effect in Norway [35]. Romer defined the difference between the economic growth rate without resource constraints and the constrained growth rate as "growth drag ", and proposed a specific method to measure "growth drag" using the Cobb-Douglas production function [36].

With the rapid development of China's urbanization process and the increasing scarcity of water and land resources, many Chinese scholars have gradually established a framework for analyzing China's problems based on Romer's model. Some Chinese scholars have calculated China's growth drag: the growth drag of land resources from 1978 to 2002 was approximately $1.75 \%$ per year [37], while the growth drag of water and land resources in China was $0.1397 \%$ and $1.3201 \%$, respectively, from 1981 to 2001 [38]. The growth drag based on China's provincial and municipal data proves that China's economic development is affected by water and land resources $[39,40]$ and there are large regional differences. Different regions face different challenges due to different resource 
endowments and geographical characteristics [41]. Some scholars build other models. Song et al. established an urban spatial econometric model from the perspective of land resources on economic growth, not only obtaining the contribution of land resources to economic growth, but also obtaining the impact on economic fluctuations [42]. Wang and $\mathrm{Li}$ explained the relationship between urban industrial water use and economic growth by constructing a new decoupling model, and found that the effect of economic scale drives the use of total industrial water use and economic growth to weaken decoupling [43].

The limitations and scarcity of water and land resources have caused resistance to economic development, which has reached a consensus in the academic community. Scholars have determined more fruitful research results in the theories, methods, and countermeasures terms. However, there are still some deficiencies. In previous studies, land resources, water resources and economic development are often split into two relatively independent relationships, and the three are not analyzed and integrated into a unified system. In addition, previous studies have mostly explored from a holistic and macro perspective, and paid little attention to the local differentiation characteristics of different types of regions, and lacked representativeness and typicality. Owing to this, this study uses the Gini coefficient to evaluate the matching degree of water resources-land resourcesGDP in Chengdu-Chongqing region, and calculates the growth drag of the development of the Chengdu-Chongqing Economic Circle on the basis of Romer's improved classic Cobb-Douglas production function; that is, it quantitatively measures the constraint of water and land resources on economic growth and the level of the regional matching degree and reveals the restraint mechanism of water and land resources on economic development. The research results have a strong scientific support for the theory and practice of enriching the matching degree of water and land resources and economic development.

\section{A Theoretical Analysis Framework of Water, Land and Economic Development}

New growth theory proposes that in any country and region, the economic development process will inevitably consume resources. According to Cobb-Douglas, the factors of production are labor force and capital, so the influence of labor force and capital on economic development should be included in the theory when discussing the relationship between water and land resources and economic development (Figure 1). Romer extended the Cobb-Douglas production function to land and water resources, forming a neoclassical growth model in which the factors of production are capital inputs, labor, and water and land resources, and their elasticity can be derived separately. Some Chinese scholars have pointed out that because of the limited resources, the consumption of resources in the previous stage must lead to the investment of economic growth in the next stage. This phenomenon is known as the "Growth tail effect" [38]. Social and economic development cannot be separated from water and land resources. If the growth rate of water and land resources is lower than the growth rate of the labor force, then the per capita ownership of water and land resources will decrease, thus, reducing the growth rate of per capita output, that is to say, creating growth drag and restricting economic development [44-46].

The population is one of the key factors that determine economic development. With the development of society and the increase in population, the demand for resources increases, and resources become more and more scarce. When some scholars study the dynamic relationship between economy and construction land, they often consider the change of population. Population change and economic growth are the main drivers of construction land expansion [47-49]. The contribution of the population to economic development is mainly reflected in the labor force. With the acceleration of urbanization, the opportunity cost of farming for farmers has gradually increased, which has accelerated the transfer of agricultural labor to non-agricultural industries, and further triggered the transformation of farmers' livelihoods and land-use patterns [50-52]. On the one hand, the transfer of agricultural labor to cities is conducive to promoting the transformation of land-use patterns, realizing the large-scale and intensive use of land in advantageous areas, and improving the economic benefits of agricultural production $[53,54]$. On the other hand, 
because farmers' production activities are profit-oriented, high-intensity land use may have a negative impact on the ecological environment, leading to a series of problems such as a reduction in biodiversity, soil pollution, and the deterioration of water quality [55-57]. Therefore, the impact of demographic changes on the economic development has two sides and is affected by multiple complex factors.

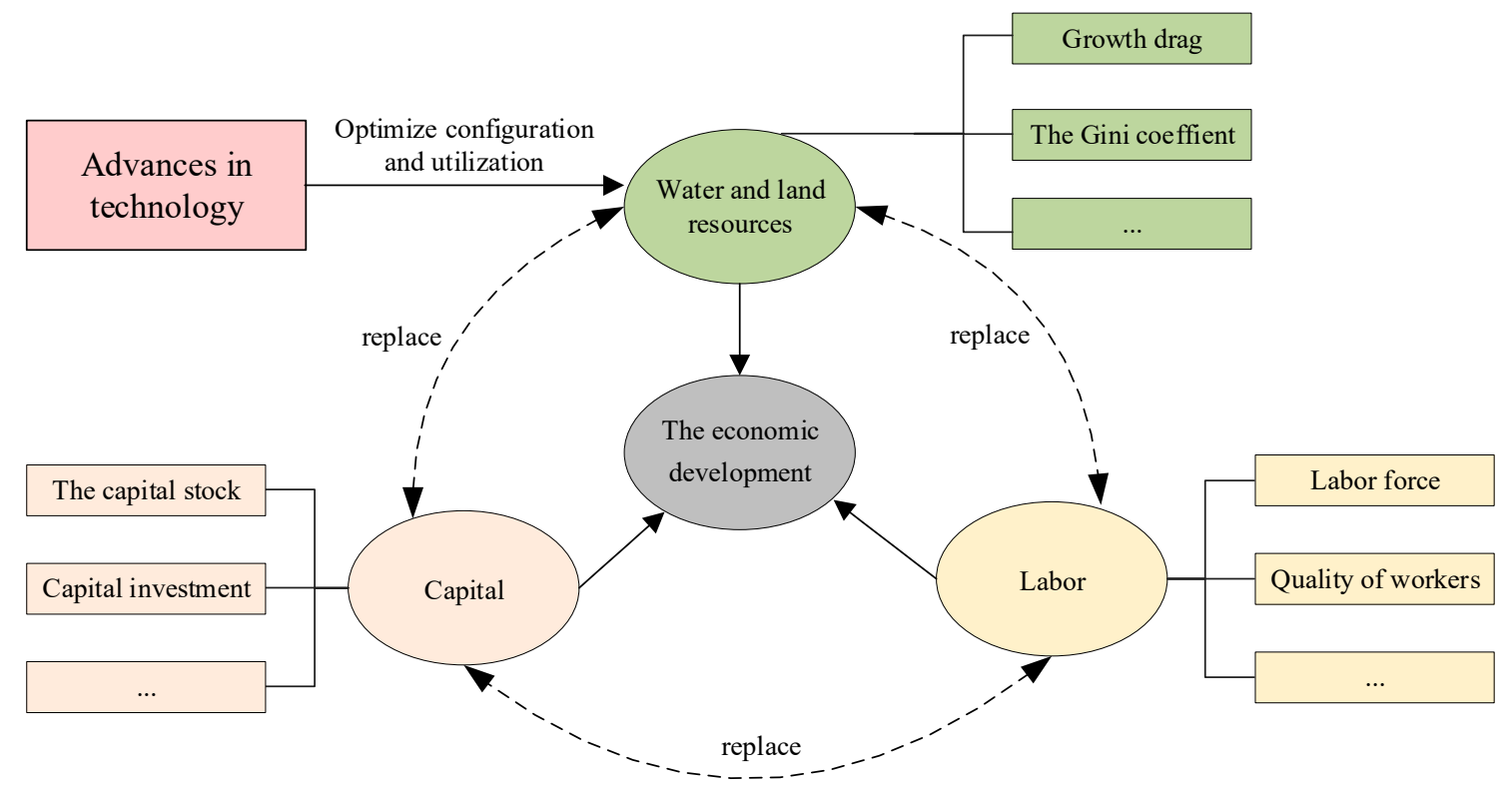

Figure 1. Analysis framework of economic development driving factors.

Red lines, such as land and environment, as well as the constraints of water and land resources on the economic development, have promoted technological innovation. Technological progress can optimize the use of existing water and land resources, and can develop more undeveloped water and land resources, such as the rational allocation of water resources, land development, rehabilitation, and intensive use of land [27,58-60]. Capital, labor force and water and land resources have substitutability in the production function. Through technological progress, effective labor and capital elements can replace the role of water and land resources to reduce absolute usage [61,62]. The government can change the extensive economic growth model, adjust the industrial structure, develop capital or technology-intensive industries in a targeted manner, and explore the potential for structural water-saving effects to relatively transfer and reduce the use of land and water resources [63-65]. An effective land resource protection policy, combined with the substitution effect of technological progress and other factors on land resources, is the key to maintaining a steady economic growth $[66,67]$.

\section{Study Site and Methodology}

\subsection{Study Site and Data Sources}

The Chengdu-Chongqing Economic Circle is located in the hinterland of southwest China, including Chengdu, Zigong, Luzhou, Deyang, Mianyang (except Beichuan County and Pingwu County), Suining, Neijiang, Leshan, Nanchong, Meishan, Yibin, Guang'an, and Dazhou (except Wanyuan City), Ya'an (except Tianquan County and Baoxing County), Ziyang and another 15 cities, as well as Chongqing City (Figure 2). The topography is relatively complex, with four types of landforms, plateaus, mountains, hills and plains. It has prominent location advantages and an important strategic position, which is located at the junction of the "Belt and Road" and the Yangtze River Economic Belt. Aiming at the Cobb-Douglas production function, this study takes labor, capital, water resources, and land resources as basic input indicators, and economic output value as output indicators. Economic growth uses gross domestic product (GDP) to measure; labor (L) uses social 
employment data; capital $(\mathrm{K})$ uses the perpetual inventory method to estimate. In order to eliminate the impact of inflation and maintain data consistency, the GDP and capital data are based on the national deflator, and comparable price adjustments were determined.

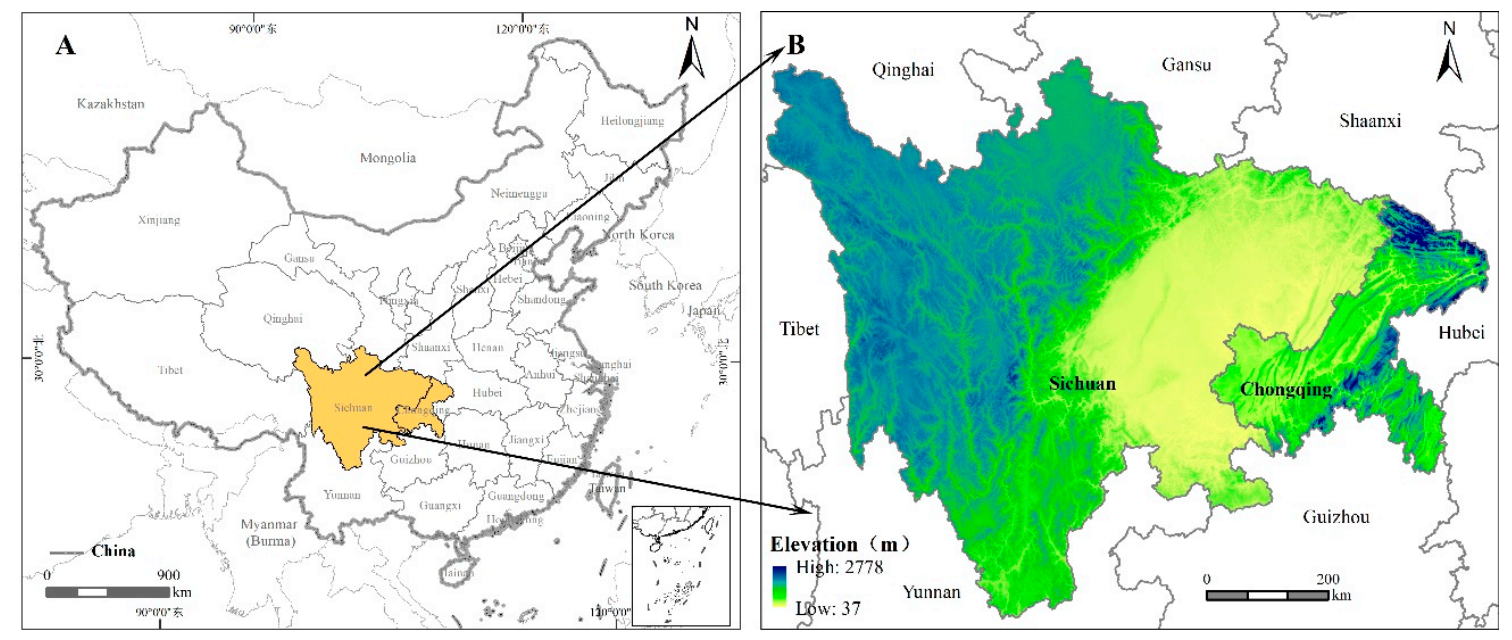

Figure 2. The location of study area. (A) depicts the location of Sichuan and Chongqing Provinces, and (B) presents the elevation information, which indicates that nearly half of the Sichuan Province is occupied by plain areas and the Chongqing is a typical hilly and mountainous region).

Based on the principles of science, reliability, and data availability, this study selects the sum of industrial water, agricultural water, and domestic water to measure the input of water resources. Water resources data (2011-2018) were obtained the Chongqing and Sichuan Water Resources Bulletins. Scholars differ greatly in the choice of land resource indicators. Some scholars use the sum of the three types of land areas, namely, the area of arable land, the area of forestry land, and the area of usable grassland as the land resource input. Considering the contribution of land resources to the output growth of the industrial sector, this study combined the characteristics of the land use structure in the Chengdu-Chongqing region and expressed the total amount of land sources by the sum of the construction land and the arable land area. The land data are from the survey data of land use changes in the relevant cities and prefectures over the years. Economic and other data (2011-2018) were obtained from China City Statistical Yearbook, Sichuan Provincial Statistical Yearbook, Chongqing Municipal Statistical Yearbook and other data.

\subsection{Methods}

\subsubsection{Estimation of Capital Stock}

This study used the perpetual inventory method to estimate the fixed capital stock $K$ [68]. The basic formula is:

$$
K_{t}=K_{t-1}(1-\delta)+I_{t}
$$

Among them, $K_{t}$ is the stock of fixed capital in period $t ; K_{t-1}$ is the stock of fixed capital in period $t-1 ; \delta$ is the discount rate; $I_{t}$ is the new fixed asset investment in period $t$.

Since no data on newly added fixed assets have been published in each city, Wang and Fan multiply the fixed asset investment in the whole society by the fixed asset investment delivery rate to calculate the newly added fixed assets before 1980 [69]. However, the length of the construction period of fixed asset investment projects is different, which makes the delivery and utilization rate of fixed asset investment vary. Therefore, when estimating new fixed assets, it was necessary to determine the period of urban investment and construction in China. Based on the actual situation in China, Ke and Xiang calculated that the weighted 
average construction period of fixed asset investment in the whole society is 3 years [70]. Additionally, then obtained:

$$
K_{t}=K_{t-1}(1-\delta)+\frac{I_{t}+I_{t-1}+I_{t-2}}{3}
$$

$I_{t-1}$ is the newly added fixed capital investment during $t-1 ; I_{t-2}$ is the newly added fixed capital investment during $t-2$. Assuming the fixed capital depreciation rate is 0.05 , the initial capital stock is estimated [71]:

$$
K_{0}=I_{0}\left(\frac{1+g}{g+\delta}\right)
$$

Among them, $I_{0}$ is the initial annual fixed capital investment; $g$ is the average growth rate of constant-price investment $I_{0}$.

\subsubsection{Calculation of Matching Coefficient of Water and Land Resources}

The water-land matching coefficient refers to the average amount of water resources per hectare of arable land in the region, which reflects the combination of water resources and arable land resources and the degree of water satisfaction to arable land. The greater the water-land matching coefficient, the richer the agricultural water resources that can be used in the region, the higher the satisfaction degree of the arable land in the region, and the more favorable the grain production of the arable land; on the contrary, the smaller the coefficient, the less water is available for agriculture. As the basic supporting condition of agricultural production, water resources are less matched in the region, which often becomes a restrictive condition for the healthy development of agriculture.

The calculation formula of water-land matching coefficient is:

$$
R_{i}=\frac{W_{i}}{L_{i}}(i=1,2, \cdots n)
$$

In the formula: $R_{i}$ is the water-land matching coefficient of the $i$-th prefecture and city; $W_{i}$ is the agricultural water use of the $i$-th prefecture and city, $L_{i}$ is the arable land area of the $i$-th prefecture and city; $n$ is the number of prefectures and cities.

The calculation formula of the regional scale water-land matching coefficient is:

$$
R=\frac{\sum_{n=1}^{n} W_{i}}{\sum_{n=1}^{n} L_{i}}
$$

In the formula: $R$ is the water-land matching coefficient of the Chengdu-Chongqing Economic Circle.

\subsubsection{Calculation of Gini Coefficient of Water and Land Resources}

In economics, the Gini coefficient can reflect the overall unfairness, and can decompose the total difference into the difference of different factors, so as to analyze the influence of different factors on the total difference. To this end, this study attempted to introduce the Gini coefficient as an indicator to assess the matching status between water and land resources and economic development, and to characterize the degree of inequality between the economy and water and land resources. Through the Gini coefficient, it was possible to explore whether the distribution of water and land resources in the region was compatible with the local economic growth, and whether the distribution was uneven in time and space.

The water-land Gini coefficient takes land resources as the basic matching object and water resources as the matching grading object. By calculating the water-land matching coefficient, the regions are sorted from low to high. In addition, the cumulative percentage of water and land resources in each region is calculated. The horizontal axis is the 
cumulative proportion of water resources, the vertical axis is the cumulative proportion of land resources, and the Lorentz curve is fitted. Water and land resources-economic Gini coefficient selects the total amount of water and land resources as the basic matching object, and uses GDP as the matching grading object to draw the Lorentz curve. Then, use definite integral to obtain the area A of the Figure sandwiched by the $0-1$ Gini curve and the $45^{\circ}$ line, and the area $B$ of the Figure sandwiched by the $0-1$ x-axis and the $45^{\circ}$ line, the Gini coefficient can be obtained:

$$
G=\frac{A}{A+B}
$$

In the formula: $G$ is the Gini coefficient, $A$ is the area of the graph between the $0-1$ Gini curve and the $45^{\circ}$ line, and $B$ is the area of the graph between the $x$-axis and the $45^{\circ}$ line.

Concerning related research results, this paper divided the matching degree of water and land resources in the Chengdu-Chongqing Economic Circle into 5 levels [72], as shown in Table 1.

Table 1. Classification of the matching degree between land and water resources and GDP.

\begin{tabular}{cccccc}
\hline Gini Coefficient Interval & $\mathbf{( 0 , 0 . 2 )}$ & $\mathbf{( 0 . 2 , 0 . 3 )}$ & $\mathbf{( 0 . 3 , 0 . 4 )}$ & $\mathbf{( 0 . 4 , 0 . 5 )}$ & $(\mathbf{0 . 5 , 1 )}$ \\
\hline The matching degree & Highly matching & Relative matching & General matching & Less matching & Extremely mismatching \\
\hline
\end{tabular}

\subsubsection{Growth Drag Model of Water and Land Resources}

The "growth drag" model reflects the degree of restriction on economic development when a certain element is restricted. Romer incorporated natural resources based on the Solow model, and established a neoclassical growth model with and without asset constraints. The difference between the steady-state per capita output growth rate obtained by the two models was defined as the growth damping of natural resources, its expression is as follows:

$$
Y(t)=K(t)^{\alpha} W(t)^{\beta} S(t)^{\gamma}[A(t) L(t)]^{(1-\alpha-\beta-\gamma)}
$$

Among them, $Y(t)$ represents the value of economic output; $K(t)$ represents the capital stock; $W(t)$ represents the amount of water resources; $S(t)$ represents the amount of land resources; $A(t)$ represents the rate of technological progress; $L(t)$ represents the number of labors. $t$ represents time; $\alpha, \beta$, and $\gamma$ represent the elasticity of capital production, water resource production, and land resource production, respectively.

Based on the Solow model:

$$
\begin{aligned}
& \bar{K}(t)=s Y(t)-\delta K(t) \\
& \bar{L}(t)=n L(t) \\
& \bar{A}(t)=g A(t)
\end{aligned}
$$

Among them, $s$ represents the savings rate, $\delta$ represents the capital depreciation rate, $n$ represents the labor force growth rate, and $g$ represents the technological progress rate.

Take the logarithm of (7) to obtain:

$$
\ln Y(t)=\alpha \ln K(t)+\beta \ln W(t)+\gamma \ln S(t)+(1-\alpha-\beta-\gamma)[\ln A(t)+\ln L(t)]
$$

Take the derivative of time on both sides of Formula (9). Since the derivative of the logarithm of a variable with respect to time is its growth rate, the growth rate function can be obtained, expressed by $g_{Y}(t), g_{K}(t), g_{W}(t), g_{S}(t), g_{A}(t)$ and $g_{L}(t)$, respectively, and the economic growth rate can be obtained:

$$
g_{Y}(t)=\alpha g_{K}(t)+\beta g_{W}(t)+\gamma g_{S}(t)+(1-\alpha-\beta-\gamma)\left[g_{A}(t)+g_{L}(t)\right]
$$


When the economy is on the path of balanced growth, to ensure that the growth rate remains unchanged, $\Delta K_{t} / k_{t-1}=Y_{t-1} / K_{t-1}$ and the growth rates of $Y(t)$ and $K(t)$ should be consistent. Simplify (10) to:

$$
g_{Y}(t)=\frac{\beta g_{W}(t)+\gamma g_{S}(t)+(1-\alpha-\beta-\gamma)(g+n)}{1-\alpha}
$$

Assuming that there are no natural resource constraints, the growth rates of water resources and land resources are both $n$. Therefore, the economic growth rate is:

$$
g_{Y}(t)=\frac{(\beta+\gamma) n+(1-\alpha-\beta-\gamma)(g+n)}{1-\alpha}
$$

In the presence of natural resource constraints, assuming that the growth rate of water and land resources is 0 , then:

$$
g_{Y}(t)=\frac{(1-\alpha-\beta-\gamma)(g+n)}{1-\alpha}
$$

The growth drag of water and land resources growth can be obtained by subtracting the two formulas:

$$
\begin{aligned}
\operatorname{drag}_{W} & =\frac{\beta n}{1-\alpha} \\
\operatorname{drag}_{S} & =\frac{\gamma n}{1-\alpha}
\end{aligned}
$$

For the calculation of labor force growth rate, this study uses the comprehensive method to calculate [73], namely:

$$
\text { rate }=\sqrt[1+2+\ldots+n]{\frac{x_{1} \cdot x_{2} \ldots x_{n}}{x_{0}^{n}}}-1
$$

In the formula: rate is the labor force growth rate, $x_{0}$ is the base period, and $x_{n}$ is the reporting period.

\subsubsection{Panel Model Regression Test}

This study selected the balanced short panel data of the Chengdu-Chongqing region from 2011 to 2018, and used the expanded Cobb-Douglas production function to establish a model and perform regression. First, the individual effect needed to be tested. Since there are generally autocorrelation disturbance items between the data of the same city (district) in different years, and the ordinary standard error is about half of the robust standard error of the cluster, the "least squares dummy variable model (LSDV)" was selected for the identification. At the same time, the mixed regression was tested, and the result was that the model had individual effects, and mixed regression should not be used. Furthermore, the joint significance test of individual effects and random effects was carried out. Since there was no strong theoretical reason to support which type of model was more suitable for estimation, this study selected the fixed effects model based on the results of Hausman's test. In consideration of the uncertainty brought by time to variables, a two-way fixed effect model was adopted for both fixed time and individuals.

\section{Results}

\subsection{Analysis of Matching Degree of Water and Land Resources}

From 2011 to 2018, the average water-land matching coefficient of the cities in the Chengdu-Chongqing Economic Circle was $2256.78 \mathrm{~m}^{3} / \mathrm{hm}^{2}$. From Table 2, the water-land matching coefficients of the six cities in Chengdu, Deyang, Mianyang, Leshan, Ya'an, and Meishan were all greater than the average of the Chengdu-Chongqing Economic Circle, the water-land matching coefficients of the remaining 10 cities were less than the average value. Compared with the amount of agricultural water resources, the spatial distribution of the 
water-land matching coefficients in various cities had obvious spatial differences (Figure 3). Chongqing, Dazhou, Yibin, Zigong, and Luzhou had the worst matching degree of water resources with arable land resources. This is due to the relative shortage of water resources and the relative abundance of arable land resources. From 2011 to 2018, Chengdu had the largest multi-year average water-land matching coefficient in the Chengdu-Chongqing Economic Circle $\left(7625.93 \mathrm{~m}^{3} / \mathrm{hm}^{2}\right)$, and Chongqing had the smallest $\left(1053.35 \mathrm{~m}^{3} / \mathrm{hm}^{2}\right)$, which showed a spatial difference compared with the provincial scale water and land matching coefficient of $2256.78 \mathrm{~m}^{3} / \mathrm{hm}^{2}$.

Table 2. The matching coefficient of water and land resources in Chengdu-Chongqing region.

\begin{tabular}{lcccc}
\hline \multicolumn{1}{c}{ City } & $\mathbf{2 0 1 1}$ & $\mathbf{2 0 1 5}$ & $\mathbf{2 0 1 8}$ & Average \\
\hline Chengdu & 7526.19 & 7712.14 & 5982.96 & 7625.93 \\
Zigong & 1407.41 & 1731.83 & 2043.39 & 1830.86 \\
Luzhou & 1516.74 & 1500.37 & 1589.72 & 1712.06 \\
Deyang & 8039.77 & 5143.17 & 5098.10 & 6136.44 \\
Mianyang & 3591.47 & 2841.30 & 2870.97 & 3457.47 \\
Suining & 1772.84 & 1934.89 & 2298.45 & 2168.10 \\
Neijiang & 1727.28 & 1700.93 & 1789.72 & 2191.84 \\
Leshan & 6111.82 & 2638.41 & 2463.10 & 4164.31 \\
Yibin & 1451.84 & 1560.41 & 1203.83 & 1769.47 \\
Nanchong & 2081.74 & 1579.75 & 1460.26 & 1960.55 \\
Dazhou & 1228.23 & 892.63 & 1364.74 & 1272.82 \\
Ya'an & 7470.44 & 4303.06 & 3239.12 & 6020.50 \\
Guang'an & 1969.50 & 2018.15 & 1176.55 & 2238.07 \\
Meishan & 6525.05 & 1334.70 & 3439.19 & 3143.44 \\
Ziyang & 2010.42 & 1707.24 & 1711.77 & 1906.99 \\
Chongqing & 1138.37 & 1064.41 & 1086.16 & 1053.35 \\
\hline
\end{tabular}

Since the decline in 2014, the average water-land matching coefficient of the ChengduChongqing Economic Circle has been maintained at 2000-2100, indicating that the matching degree of water and land resources has declined in recent years and the distribution of water and land is uneven (Figure 4).

\subsection{Analysis of Water and Land Resources-Economic Matching Degree}

This study sorts out and processes the data of water usage, land resource usage, GDP and other data in each region of the Chengdu-Chongqing Economic Circle from 2011 to 2018, and calculates the GDP corresponding to unit water resources and land resources in each region. The Lorentz curve is drawn according to the construction method of the Gini coefficient, and the current situation of matching between water and land resources and GDP was obtained.

From the Lorentz curve in Figure 5, it can be calculated that the average Gini coefficient of water and land resources in the Chengdu-Chongqing Economic Circle from 2011 to 2018 was 0.32 , which is within a reasonable range, indicating that the overall spatial distribution of water and land resources is relatively balanced, but there is a big gap from the degree of high matching.

In Figure 6, the area formed by the water resources-GDP Lorentz curve and the $45^{\circ}$ line in 2018 was 0.0944 . According to the meaning of the Gini coefficient, the regional Gini coefficient of water resources and GDP in the Chengdu-Chongqing Economic Circle in 2018 was 0.1888 . This value indicates that the utilization of water resources in the national economy of the region was highly matched. Similarly, the regional Gini coefficient of land resources and GDP was 0.3231, which indicates that the land resource utilization in the national economy of the region was relatively matched and even. In the two Lorentz curves, the land resources-GDP Lorentz curve is farther away from the absolute average line, which means that the balance of water resources was better than that of land resources, and the degree of matching of land resources to economic growth was lower. 


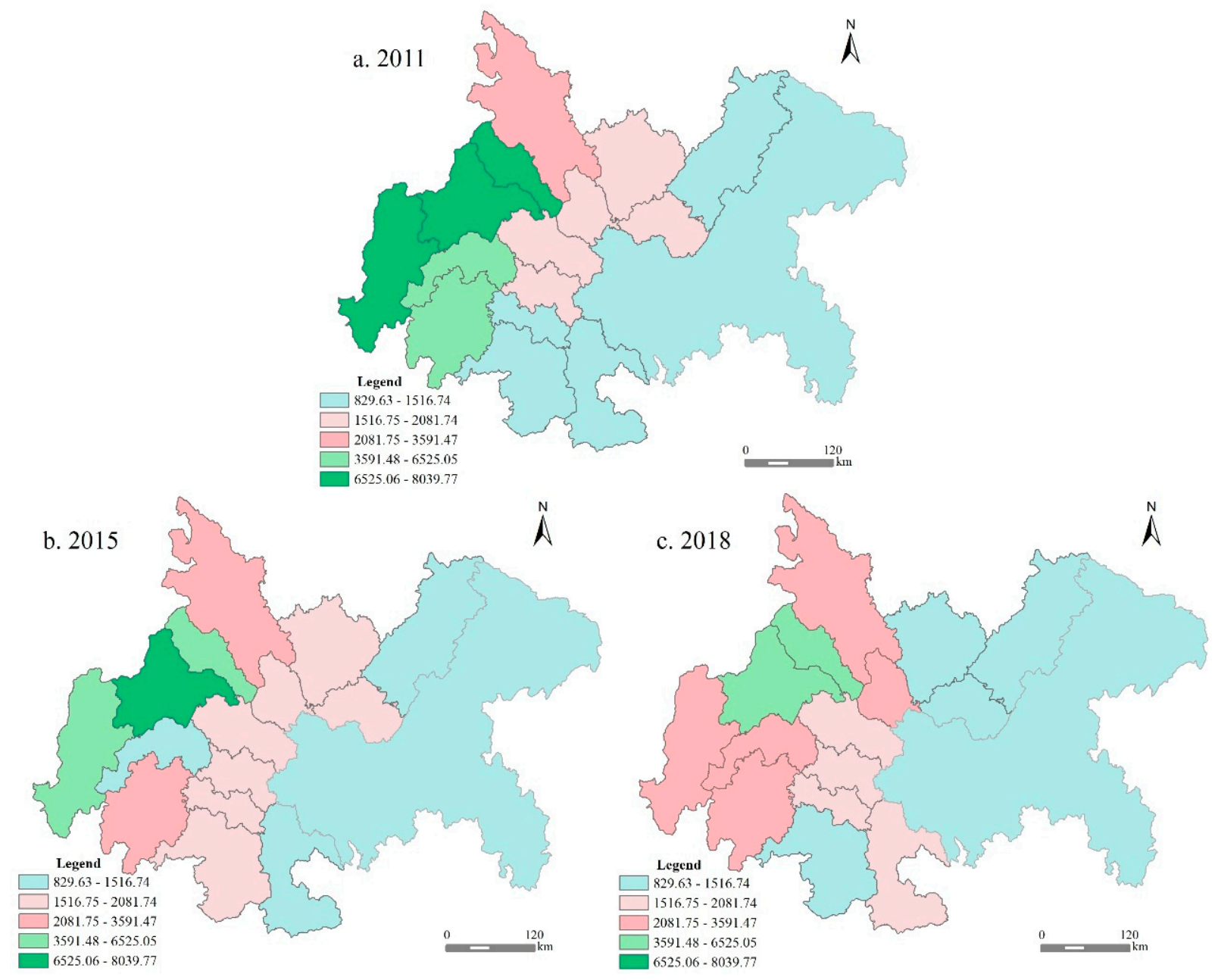

Figure 3. The spatio-temporal distribution characteristics of the matching coefficient of water and land resources in the Chengdu-Chongqing region from 2011 to 2018.

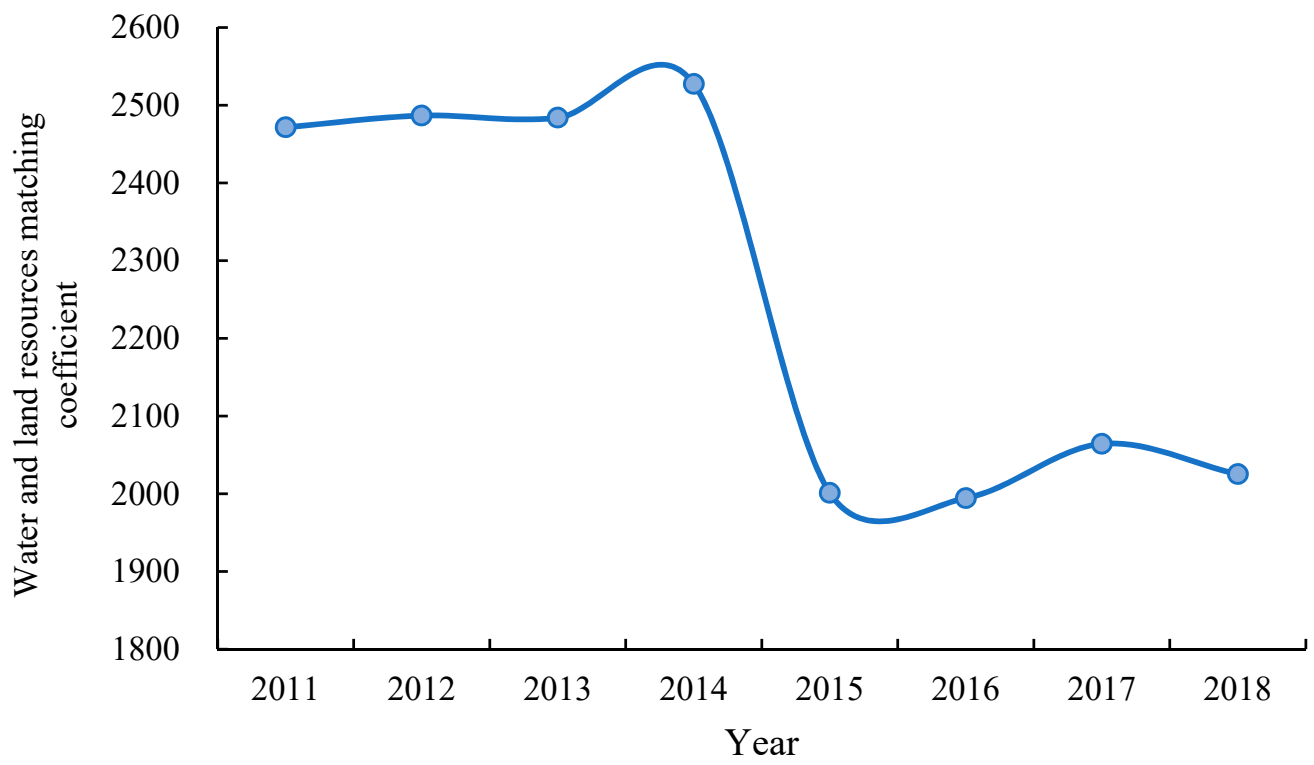

Figure 4. Change trend of water and land resources matching coefficient from 2011 to 2018. 


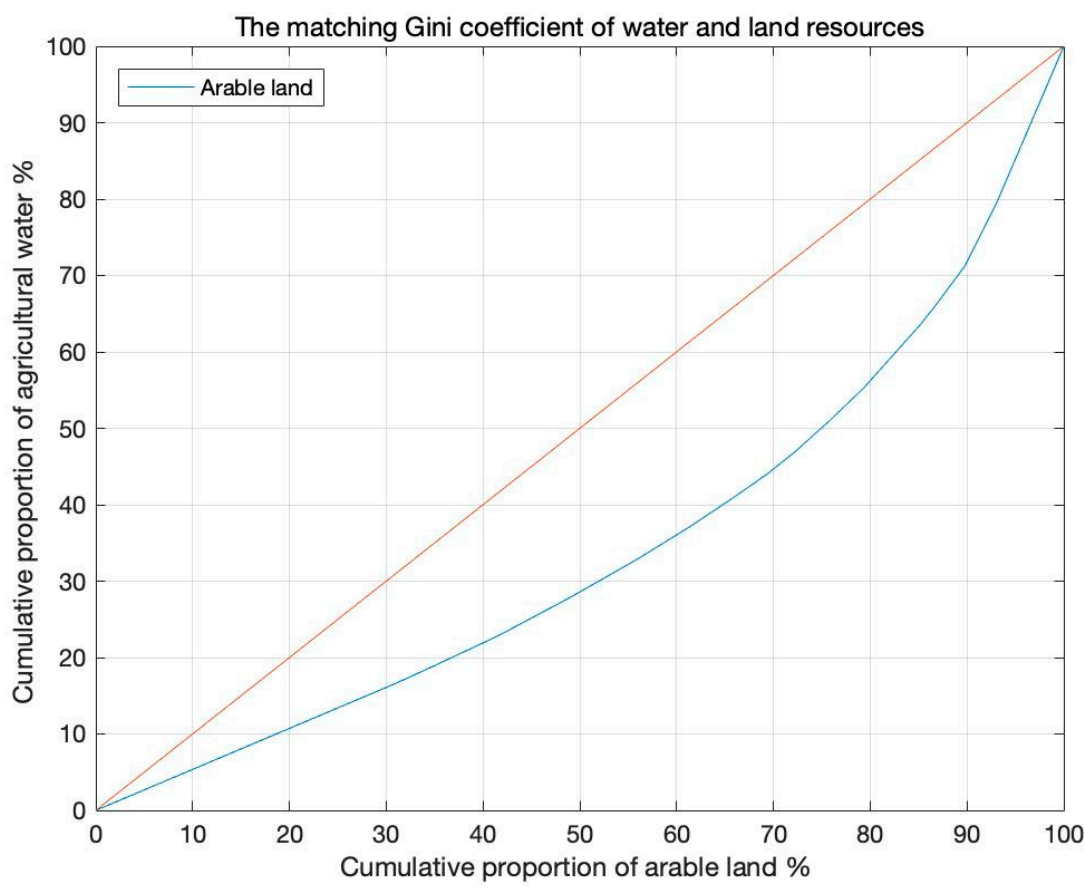

Figure 5. Lorentz Curve of Water and Land Resources Matching in Chengdu-Chongqing Economic Circle in 2018.

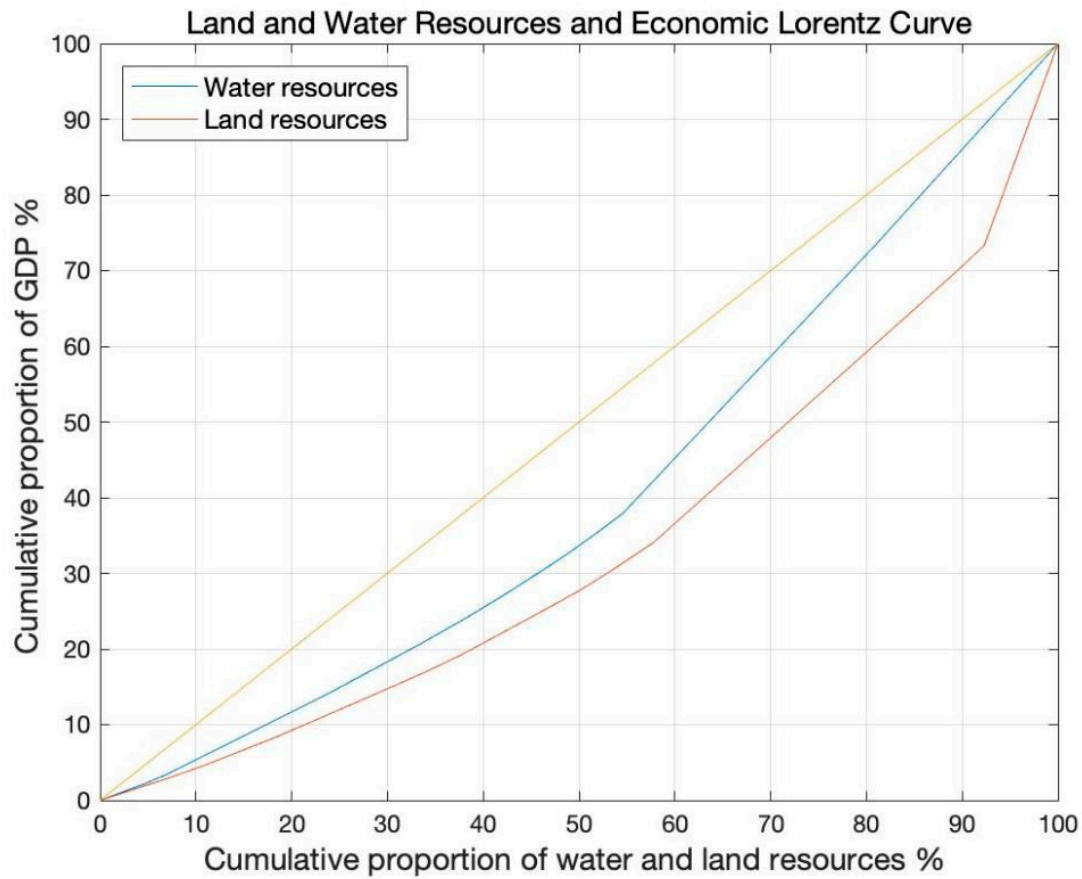

Figure 6. Water resources, land resources and GDP Lorenz curve in the Chengdu-Chongqing Economic Circle in 2018.

Further analysis of the Gini coefficient of water and land resources and the economic development from 2011 to 2018 (Figure 7) found that the Gini coefficient of water resources was relatively stable, rising slightly in 8 years and fluctuating between 0.1491 and 0.1888 . It can be seen that water resources were highly matched with GDP in recent years, well adapted to the needs of the industrial development, and the distribution was relatively reasonable and even. The Gini coefficient of land resources was at a relatively high level and fluctuated greatly. In 2011-2014, land resources and GDP were in a relative matching 
degree, and the matching degree showed a downward trend after 2014. Its matching degree was lower than that of water resources, which may be because the complex and diverse terrain environment of the Chengdu-Chongqing Economic Circle had a restrictive effect on the degree of regional land resource utilization.

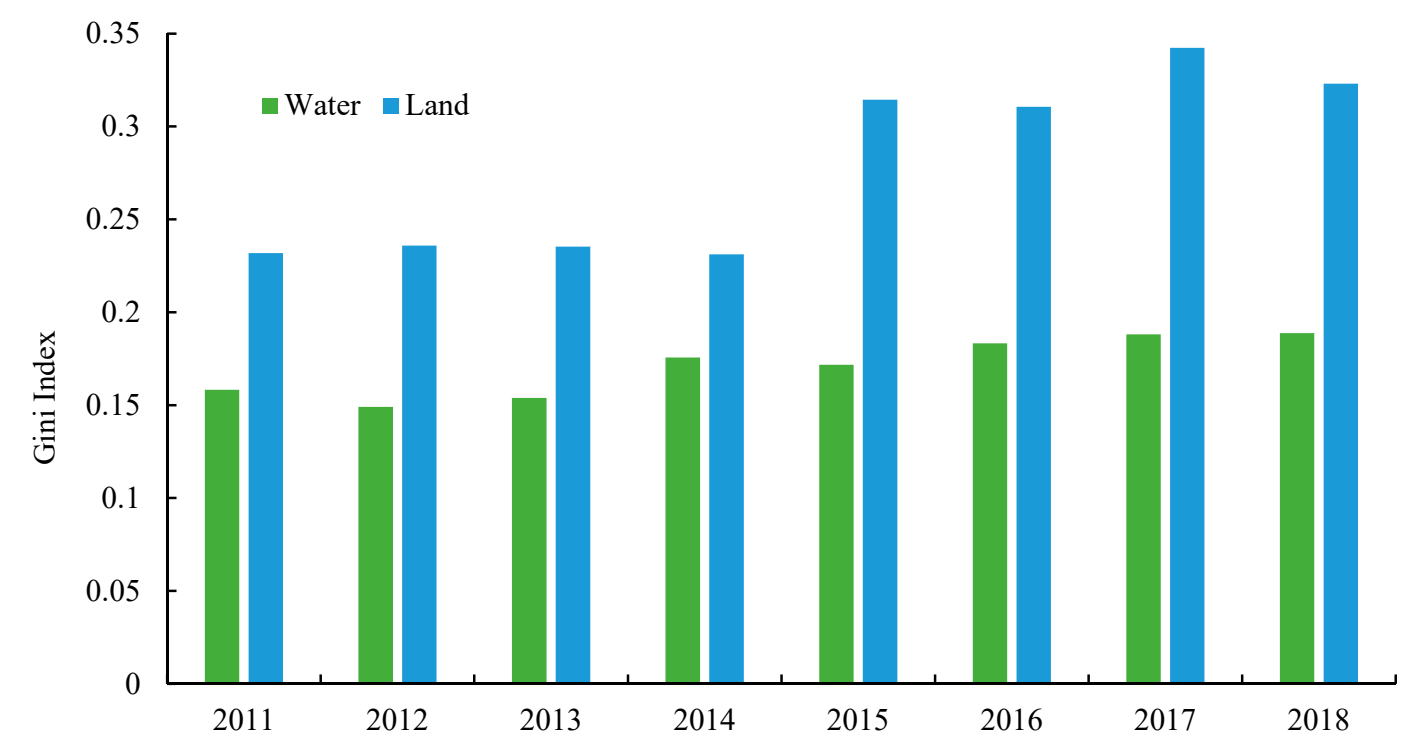

Figure 7. Gini Index of water resources, land resources and GDP in Chengdu-Chongqing Economic Circle from 2011 to 2018 .

\subsection{Analysis of the Growth Drag of Water and Land Resources \\ 5.3.1. Panel Model Regression Results}

According to Equations (7)-(9): according to the expanded Cobb-Douglas production function, the logarithm of GDP, labor force, capital, water resources and land resources of each city in Chengdu-Chongqing Economic Circle from 2011 to 2018 were taken to carry out a panel regression analysis.

The function fitting effect was better, labor and capital were significant at $1 \%$, and water and land resources were significant at $5 \%$ (Table 3). It can be seen from Table 2 that the function fitting effect was better, labor and capital were significant at $1 \%$, and water and land resources were significant at $5 \%$. The results show that the four variables were closely related to output, and water and land resources can explain changes in GDP to a certain extent. Among them, the coefficients of labor and capital were relatively large, 0.891 and 0.307 , respectively. It can be seen that the GDP was more sensitive in terms of capital stock and labor, which means that the development of the region still relies more on capital and labor input. In particular, the increase in labor was of great importance to economic development, which reflects that its economic development stage was still relatively low.

The biggest reason for labor flexibility was that most of the Chengdu-Chongqing Economic Circle was still dominated by labor-intensive industries, and there was a large demand for labor. Second, due to the continuous expansion of the industrial scale in the Chengdu-Chongqing region, the demand for labor continues to increase. Due to its high demand for labor, there has been an obvious phenomenon of population return in recent years. From 2012 to 2018, the permanent population of Sichuan Province increased by 2.99 million, returning to the level of 2000, and the population showed a trend of first decreasing and then increasing.

The elastic coefficients of water resources and land resources are relatively small, with 0.136 and 0.0894 , respectively. It can be seen that the development and utilization of water resources contribute more to the economic development of the Chengdu-Chongqing Economic Circle. The Sichuan-Chongqing region relies on the Yangtze and Jialing Rivers, and water resources play an important role in the development of their industries. Areas with a relatively advanced level of economic development, such as the plains of Western 
Sichuan, the hills of Central Sichuan, and Southern Sichuan, are relatively scarce of water resources and still have great potential. However, as far as land resources are concerned, due to the natural geographic characteristics of plain areas, developable land resources have been converted into current construction land earlier, and the land potential is not much reserved. Therefore, the further development and utilization of water resources has a more significant effect on the economic development, while the impact of land resources is relatively weak.

Table 3. Results of the extended Cobb-Douglas production function model.

\begin{tabular}{ccc}
\hline & $f e$ & $r e$ \\
\hline \multirow{2}{*}{$n$} & $0.136^{*}$ & $0.125^{*}$ \\
& $(0.0577)$ & $(0.0566)$ \\
\hline \multirow{2}{*}{$\ln$} & $0.0894^{*}$ & $0.115^{* *}$ \\
& $(0.0382)$ & $(0.0364)$ \\
\hline \multirow{2}{*}{$\ln$} & $0.891^{* * *}$ & $0.730^{* * *}$ \\
& $(0.157)$ & $(0.0782)$ \\
\hline \multirow{2}{*}{$\ln k$} & $0.307^{* * *}$ & $0.286^{* * *}$ \\
& $(0.0217)$ & $(0.0210)$ \\
\hline \multirow{2}{*}{ cons } & $-3.565^{* * *}$ & $-2.670^{* * *}$ \\
& $(0.958)$ & $(0.509)$ \\
\hline Standard errors in parentheses. ${ }^{*} p<0.05,{ }^{* * *} p<0.011^{* * *} p<0.001$. & 128 \\
\hline
\end{tabular}

\subsubsection{Water and Land Resource Damping Coefficient}

The rate of change of water and land resources was calculated by the comprehensive method, and combined with the panel regression results, the growth drag of water and land resources was measured, and the two drags were added to obtain the total damping of the area. The result is shown in Figure 8.

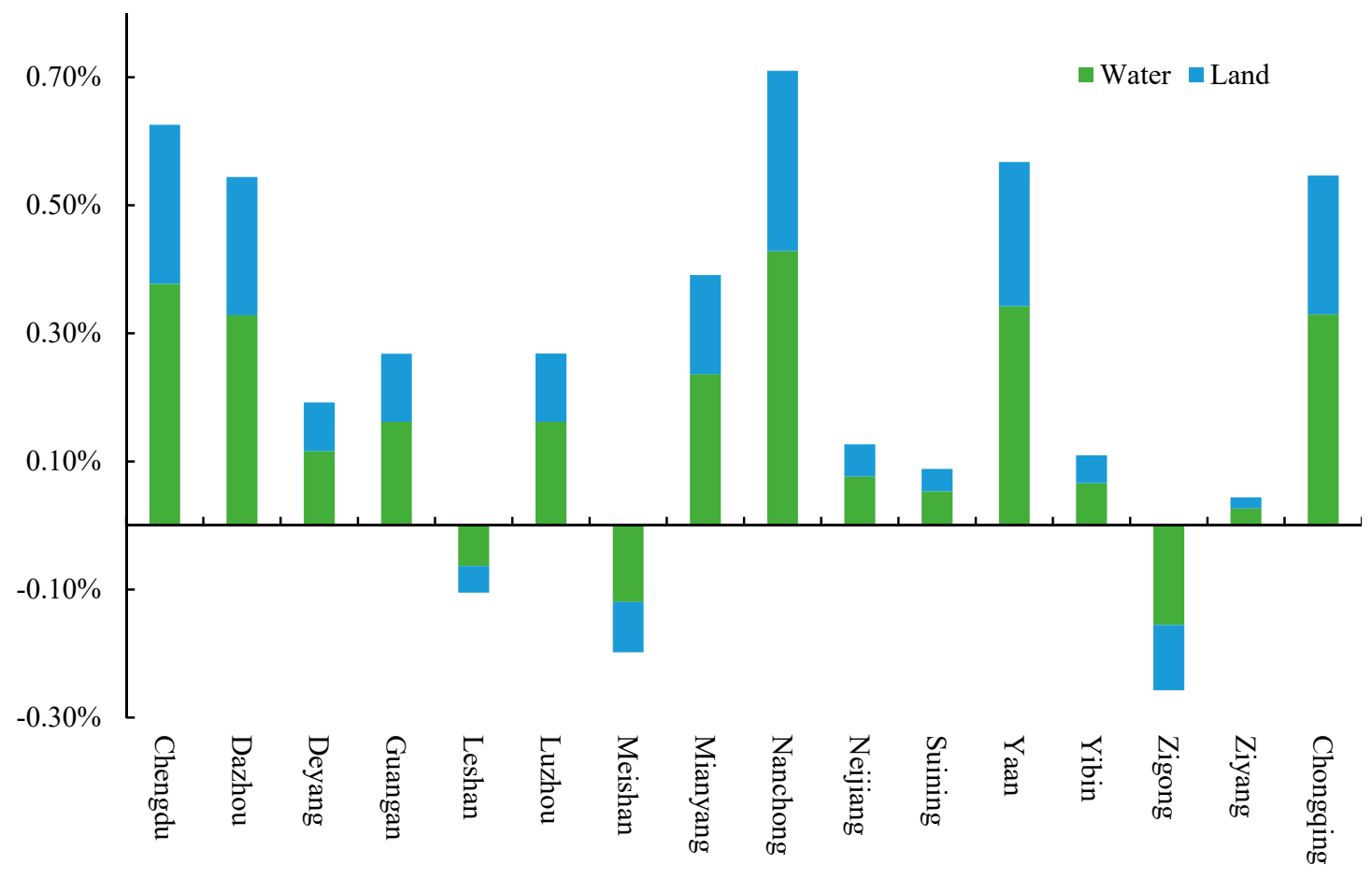

Figure 8. Water and land resources growth drag of cities in Chengdu-Chongqing Economic Circle. 
In general, the damping coefficients of water and land resources in all regions of the Chengdu-Chongqing Economic Circle were relatively low, all below $0.7 \%$. The first reason is that the elasticity of the capital output was relatively small. At present, the Chengdu-Chongqing Economic Circle has fewer capital-intensive industries, with laborintensive industries dominating. Secondly, due to the generally low growth rate of labor, the Economic Circle is still in the early stage of development, and the industrial development is still immature. Most areas are mountainous and hilly, so the ability to attract labor is limited. In addition, the low elasticity of water and land resources is also the reason for low damping. At present, the development of various regions is relatively weakly dependent on natural resources, and the impact of land and water resources on the economy is relatively small. In contrast, the damping of water resources is greater than that of land resources. It can be seen that water resources are still an important factor restricting economic development.

There are large regional differences in various cities. From Figure 8, the damping of water and land resources in Leshan, Meishan and Zigong areas were all negative values. This means that the incremental supply of urban land was not only unable to promote urban economic growth, but was also being suppressed. The reason was that the labor force growth rate in these regions was negative, that is, the net population outflow. Therefore, even if the growth rate of natural resources was zero, it would not hinder economic growth. The main reasons for the outflow of the population in these areas are their small initial scale of economy and population, a low administrative level and urbanization level, and poor development foundation. The pains of industrial transformation have led to a weakening of the ability to absorb the local labor force, shrinking the original large-scale labor-intensive low-end industry jobs, especially in the third-tier construction of industrial cities represented by Leshan City, which will inevitably lead to population loss. The mountainous terrain conditions of Leshan lead to the frequent occurrence of geological disasters, and the shortage of water and land resources in Zigong has also led to the outflow of labor.

The labor transfer and relatively slow capital inflow have caused the marginal return of urban land development and utilization to be lower than its marginal cost, making the utilization and development of urban land have an "abnormal" negative effect on urban economic growth. The results show that the resources in these areas are in a surplus stage, and the outflow of population leads to a waste of resources.

Except for the above three regions, the damping coefficients of water and land resources in the other regions were all positive, indicating that natural resources restrict economic development to a certain extent. Among them, Nanchong, Chengdu and Ya'an had the largest total damping capacity. The reason is that the labor force growth rate in these areas is relatively high. Nanchong and Chengdu are rich in water and land resources, which have better development conditions and a greater ability to attract a population. Moreover, Nanchong and Chengdu have a relatively mature industrial development, a high degree of urbanization, and more labor inflows. The main reasons for the rapid growth of the labor force in Ya'an are: On the one hand, its population base and labor force are small. In the early stage of economic development, its output mainly relied on agriculture, and most of it was mountainous and hilly, leading to economic backwardness. Based on a low level, a smaller population increase can bring about a larger growth rate. On the other hand, in recent years, the government has actively promoted poverty alleviation policies and industrial reforms in Ya'an, so the population has grown to a certain extent.

\section{Discussion and Conclusions}

\subsection{Discussion and Limitation}

What factors can reduce the constraints of land and water resources on economic growth, and what can we do to reduce growth drag?

Growth drag is directly proportional to the elastic coefficients of water and land resources, that is, reducing the elastic coefficient can reduce the "tail effect" of economic 
growth. Its economic significance is to reduce the role of land in the economy. This also provides another explanation for economic growth that does not rely excessively on resources, but technological progress. A similar explanation can be made for the elasticity coefficient of the capital. As the elasticity coefficient of the capital decreases, so does the growth drag. Therefore, economic growth cannot rely on the increase in capital stock, and technological progress is the key. It is necessary to transfer economic growth to technological progress. Damping is directly proportional to the labor force growth rate. The smaller the labor growth rate, the slower the rate of reduction in per capita natural resources, the smaller the growth rate of the per capita average output on the path of balanced growth, and the smaller the resistance of natural resources to economic growth. The population continues to rise steadily. On the one hand, it provides a wealth of labor for economic growth; on the other hand, economic growth will absorb labor, and the labor force growth rate will increase accordingly. If you want to reduce the increase in the damping effect caused by the increase in the number of employees, you must maintain a moderate population size, while improving the quality of the population and increasing effective labor [74].

There is no doubt that we should pay attention to the restrictions and constraints of water and land resources on economic development, but we should not exaggerate the growth drag of water and land resources. It can be seen that the development of the Chengdu-Chongqing Economic Circle is not greatly constrained by water and land resources. The overall water and land resources are relatively matched with the economy, and there are large internal differences. Romer, when analyzing the complexity of resources and economic growth, believed that the share of land is the product of the real rental price of land and the land-output ratio [36]. Although the real rental price rarely decreases, the land-GDP ratio has been steadily declining; therefore, the share of land has also fallen, and the actual situation in China is also the same. Similarly, the share of water resources is also declining, and the decline in the share of land and water means a decline in "growth drag". The Chinese scholar Lu also determined a similar judgment [75]. He pointed out that the role of natural resources in China's economic growth is declining. The fact that the share of water and land resources has declined also means that the substitution elasticity between water and land resource inputs and other inputs is greater than 1 . Therefore, the economy has shifted to those production methods that relatively seldom use water and land resources, so as to deal with the increasing scarcity of water and land resources.

From a short-term perspective, technological progress can give full play to the role of factor substitution and alleviate resource constraints; however, in the long run, resource constraints can be finally solved only when factor substitution and industrial structure adjustment work together to promote the development of non-resource-based industries [76]. Although it was concluded from the above analysis that factor substitution can alleviate resource constraints in the short term, land and water resources, as a basic input factor, are difficult to be effectively replaced by factors such as capital and labor when the development level of China's primary and secondary industries and the level of urbanization are relatively low. At the same time, due to the strict assumptions on the elasticity of factor substitution, it is difficult to meet the actual situation, so the substitution relationship between factors needs to be further explored and studied.

In addition, there are still some shortcomings in the study: (1) The regulation mechanism of water and land resources needs to be further deepened. The water consumption and land resource requirements of different industries vary greatly, and the industrial structure is more affected by the local resource endowments, so it is not possible to improve the utilization efficiency of water and land resources by completely changing the industrial structure. (2) Due to the availability of data and the choice of indicators, the analysis in this study failed to fully consider resource constraints, and only the area of arable land resources and construction land was considered in the land resources. 


\subsection{Conclusions and Implications}

\subsubsection{Conclusions}

Based on the theory of economic growth, this study combined the panel regression test method with the Gini coefficient method, and used the panel fixed effect model to build the "growth drag" model of water and land resources in the Chengdu-Chongqing Economic Circle. The damping effect of water and land resources on the economic growth and the matching degree of water and land resources and the economy in the Chengdu-Chongqing Economic Circle were studied in depth. The following conclusions were drawn:

Water and land resources have a certain restraining effect on economic development, and their matching degree with economic development is relatively low. The restraining effect is often realized through the high contribution of capital in the industry, the high growth of the population and the dependence of the economy on water and land resources. The greater the dependence on capital stock, the faster the growth rate of the labor force, the more the industry depends on water and land resources, and the greater the growth damping of water and land resources. The growth damping of the Chengdu-Chongqing Economic Circle is relatively small. The damping of water resources is greater than the damping of land resources, and the matching degree between water resources and land resources, water and land resources and economic development is relatively high.

There are large differences within the region. The damping of water and land resources in the southwestern part of the Chengdu-Chongqing Economic Circle is negative in Leshan, Meishan, and Zigong, while the damping in Chengdu and Nanchong in the west is relatively large. The water and land resources in Chengdu-Chongqing Economic Circle are relatively rich, but for resource-scarce regions, the mechanism and approach of how to use a market mechanism to utilize internal and external resources, especially foreign resources, to alleviate resource constraint still need to be studied.

\subsubsection{Policy Implications}

The Chengdu-Chongqing Economic Circle is a central city cluster in Southwest China. It plays an important role in the country's strategy of improving regional cooperation mechanisms and creating coordinated development. The matching and balance of water resources and land resources is one of the key factors for achieving sustainable economic growth. Based on the above research, this study proposes the following policy measures to promote the optimal allocation of land and water resources, economic growth, and the sustainable use of resources.

From the perspective of water and land resources, expanding the total amount of water and land resources and increasing supply should be taken to solve the problem of the damping effect of water and land resources from the source, to realize sustainable economic development. Governments should increase investment in the construction of water conservancy facilities in the precipitation-rich areas of the Chengdu-Chongqing Economic Circle to store more water resources. For land resources, governments should scientifically carry out land development and consolidation, optimize the structure of land use, and take the road of intensification. Strengthening land consolidation and reclamation, prioritizing plans and arrangements for land that can be used after transformation, and effectively using plain land resources should also be taken. The proportion of unused land in Sichuan Province is relatively large. As the pressure on land resources becomes greater, corresponding measures must be taken for unused land or land that does not produce economic benefits to make it effective.

Change the way of resource utilization and give full play to the role of technology in economic growth. Due to the limitation of natural supply resources, as the population continues to grow and the scale of cities continues to expand, resources will still be an important factor restricting economic growth. At the same time, the dependence on economic growth must be transferred to technological progress to give full play to the mitigation effect of technological progress on resource constraints and to reduce the economy's dependence on resources. The government should increase investment in technology 
development, such as researching and developing water-saving varieties and adjusting the industrial structure, to play the role of factor substitution and improve the efficiency of factor allocation. The government can also set up incentive funds to encourage water conservation and the protection of water resources.

In terms of labor-related policies, it is necessary to rely on the resource advantages of universities to accelerate the optimization of the employment structure, and reduce the damping effect by promoting the rational and orderly transfer of the employed population from the primary industry to the secondary and tertiary industries. For areas with different damping, different policies can be adopted. The negative damping region: The damping values of water and land resources in Leshan, Meishan and Zigong are all negative. This shows that the resources in these areas are surplus, and the outflow of the population has led to the waste of resources. Therefore, for these regions, the introduction of talents and labor is the key to promoting economic development. Natural resources should be used to develop advantageous industries, and with the development of industries, talents will be attracted to further promote economic development and form a virtuous circle. The positive damping region: It reflects that natural resources restrict economic development to a certain extent. For areas such as Nanchong and Chengdu with higher damping and higher levels of economic development, an appropriate scale of labor should be maintained, while the quality of the population and effective labor should be improved. In addition, the distribution of labor should be consistent with the distribution of industries to further promote economic growth.

Author Contributions: Conceptualization, Y.P. and L.M.; methodology, Y.P.; software, H.T.; validation, Y.P., L.M. and H.T.; formal analysis, Y.W.; investigation, Z.Y.; resources, Y.P.; data curation, H.T.; writing—original draft preparation, L.M.; writing—review and editing, Y.P.; visualization, L.M.; supervision, Y.W.; project administration, H.T.; funding acquisition, L.M. and H.T. All authors have read and agreed to the published version of the manuscript.

Funding: Founded by China Postdoctoral Science Foundation (No. 2021M693709); Social Science Planning Research Doctoral Program of Chongqing Social Science Planning Office (Grant No. 2020BS43); Humanity and Social Science Youth Foundation of Ministry of Education Project (Grant No. 17YJC630136); The Fundamental Research Funds for the Central Universities (Grant No. 2021CDJSKJC02).

Institutional Review Board Statement: Not applicable.

Informed Consent Statement: Not applicable.

Data Availability Statement: Not applicable.

Conflicts of Interest: The authors declare no conflict of interest.

\section{References}

1. Daly, H.E. When smart people make dumb mistakes. Ecol. Econ. 2000, 1, 1-2. [CrossRef]

2. Peng, L.; Deng, W.; Tan, J.; Lin, L. Matching relationship between land and water resources utilization and economic growth in Hengduan Mountain. Acta Geogr. Sin. 2020, 75, 1996-2008.

3. Wei, X.; Wang, J.; Wu, S.; Xin, X.; Wang, Z.; Lin, W. Comprehensive evaluation model for water environment carrying capacity based on VPOSRM framework: A case study in Wuhan, China. Sustain. Cities Soc. 2019, 50, 101640. [CrossRef]

4. Liu, G.; Hu, F.; Wang, Y.; Wang, H. Assessment of Lexicographic Minimax Allocations of Blue and Green Water Footprints in the Yangtze River Economic Belt Based on Land, Population, and Economy. Int. J. Environ. Res. Public Health 2019, 16, 643. [CrossRef] [PubMed]

5. Zhao, J.; Li, M.; Guo, P.; Zhang, C.; Tan, Q. Agricultural water productivity oriented water resources allocation based on the coordination of multiple factors. Water 2017, 9, 490. [CrossRef]

6. Liu, Y.; Wang, S.; Chen, B. Water-Land Scarcity Risk Nexus in the National Trade System Based on Multiregional Input-Output and Ecological Network Analyses. DEStech Transactions on Environment, Energy and Earth Sciences 2018. Available online: https:/ / www.dpi-proceedings.com/index.php/dteees/article/view/27893 (accessed on 10 December 2020).

7. Bacca, E.J.M.; Knight, A.; Trifkovic, M. Optimal land use and distributed generation technology selection via geographic-based multicriteria decision analysis and mixed-integer programming. Sustain. Cities Soc. 2020, 55, 102055. [CrossRef] 
8. Moein, M.; Asgarian, A.; Sakieh, Y.; Soffianian, A. Scenario-based analysis of land-use competition in central Iran: Finding the trade-off between urban growth patterns and agricultural productivity. Sustain. Cities Soc. 2018, 39, 557-567. [CrossRef]

9. 2005 China Land and Resources Bulletin; National Land \& Resources Information, 2006; pp. 26-30. Available online: http:/ /www.gov. cn/jrzg/2006-04/28/content_268770.htm (accessed on 10 December 2020).

10. UNESCO. The United Nations World Water Development Report 2017; UNESCO: Paris, France, 2017.

11. Jia, Z.; Cai, Y.; Chen, Y.; Zeng, W. Regionalization of water environmental carrying capacity for supporting the sustainable water resources management and development in China. Resour. Conserv. Recycl. 2018, 134, 282-293. [CrossRef]

12. Qi, Z.; Xiao, C.; Zhang, B.; Liang, X. Generalized index of regional socio-economic consumption level of water resource. J. Water Supply Res. Technol. 2020, 69, 113-121. [CrossRef]

13. Song, X.; Shi, P.; Jin, R. Analysis on the contradiction between supply and demand of water resources in China owing to uneven regional distribution. Arid Zone Res. 2005, 22, 162-166.

14. Zhao, M.; Chen, Z.; Zhang, H.; Xue, J. Impact Assessment of Growth Drag and Its Contribution Factors: Evidence from China's Agricultural Economy. Sustainability 2018, 10, 3262. [CrossRef]

15. Cai, X. Implementation of holistic water resources-economic optimization models for river basin management-reflective experiences. Environ. Model. Softw. 2008, 23, 2-18. [CrossRef]

16. Birol, E.; Koundouri, P.; Kountouris, Y. Assessing the economic viability of alternative water resources in water-scarce regions: Combining economic valuation, cost-benefit analysis and discounting. Ecol. Econ. 2010, 69, 839-847. [CrossRef]

17. Xuan, W.; Quan, C.; Shuyi, L. An optimal water allocation model based on water resources security assessment and its application in Zhangjiakou Region, northern China. Resour. Conserv. Recycl. 2012, 69, 57-65. [CrossRef]

18. Kragt, M.E. Hydro-economic modelling in an uncertain world: Integrating costs and benefits of water quality management. Water Resour. Econ. 2013, 4, 1-21. [CrossRef]

19. Davies EG, R.; Simonovic, S.P. Global water resources modeling with an integrated model of the social-economic-environmental system. Adv. Water Resour. 2011, 34, 684-700. [CrossRef]

20. Wu, F.; Zhan, J.; Zhang, Q.; Sun, Z.; Wang, Z. Evaluating impacts of industrial transformation on water consumption in the Heihe River basin of northwest China. Sustainability 2014, 6, 8283-8296. [CrossRef]

21. Ji, X.; Han, M.; Ulgiati, S. Optimal allocation of direct and embodied arable land associated to urban economy: Understanding the options deriving from economic globalization. Land Use Policy 2020, 91, 104392. [CrossRef]

22. Tan, S.K.; Rao, Y.X.; Zhu, X.B. Study on the influence of land investment on regional economic growth. China Popul. Resour. Environ. 2012, 22, 61-67.

23. Long, H. Land Use Transitions and Rural Restructuring in China; Springer: Berlin/Heidelberg, Germany, 2020.

24. Liang, X.; Jin, X.; Ren, J.; Gu, Z.; Zhou, Y. A research framework of land use transition in Suzhou City coupled with land use structure and landscape multifunctionality. Sci. Total Environ. 2020, 737, 139932. [CrossRef]

25. Liu, Y.; Li, J.; Yang, Y. Strategic adjustment of land use policy under the economic transformation. Land Use Policy 2018, 74, 5-14. [CrossRef]

26. Li, T.; Liao, H.; Yang, W.; Zhang, W.; Shi, J. Urbanization quality over time and space as well as coupling coordination of land, population and industrialization in Chongqing. Econ. Geogr. 2015, 35, 65-71.

27. Ge, D.; Zhou, G.; Qiao, W.; Yang, M. Land use transition and rural spatial governance: Mechanism, framework and perspectives. J. Geogr. Sci. 2020, 30, 1325-1340. [CrossRef]

28. Xie, H.; Zhu, Z.; Wang, B.; Liu, G.; Zhai, Q. Does the expansion of urban construction land promote regional economic growth in China? Evidence from 108 cities in the Yangtze River Economic Belt. Sustainability 2018, 10, 4073. [CrossRef]

29. Du, G.; Cai, Y. Technical Efficiency of Built-up Land in China's Economic Growth during 1997-2007. Progr. Geogr. 2010, 6, 12.

30. Sawaya, K.E.; Olmanson, L.G.; Heinert, N.J.; Brezonik, P.L.; Bauer, M.E. Extending satellite remote sensing to local scales: Land and water resource monitoring using high-resolution imagery. Remote Sens. Environ. 2003, 88, 144-156. [CrossRef]

31. Dong, W.; Yang, Y.; Zhang, Y.F. Coupling effect and spatiotemporal differentiation between oasis city development and water-land resources. Resour. Sci. 2013, 35, 1355-1362.

32. Wang, W.; Lu, N.; Wang, X. Spatial Matching Pattern of Water and Soil Resources in the Yellow River Delta. J. Water Resour. Water Eng. 2014, 25, 66-70.

33. Zhang, J.H.; Li, J.; Tang, Y. Analysis of the spatio-temporal matching of water resource and economic development factors in China. Resour. Sci. 2012, 34, 1546-1555.

34. Nordhaus, W.D.; Stavins, R.N.; Weitzman, M.L. Lethal model 2, The limits to growth revisited. Brook. Pap. Econ. Act. 1992, 1992, 1-59. [CrossRef]

35. Bruvoll, A.; Glomsrød, S.; Vennemo, H. Environmental drag: Evidence from Norway. Ecol. Econ. 1999, 30, 235-249. [CrossRef]

36. Romer, D. Advanced Macroeconomics, 2nd ed.; Shanghai University of Finance \&Economics Press: Shanghai, China, 2001; pp. 30-38.

37. Xue, J.; Wang, Z.; Zhu, J.; Wu, B. Analysis of the "tail effect" of China's economic growth. Financ. Res. 2004, 30, 5-14.

38. Xie, S.; Wang, Z.; Xue, J. Analysis of the "Tail-effect of Growth" of Soil and Water Resources in China's Economic Development. Manag. World 2005, 7, 22-25.

39. Cao, X.; Jin, X.; Zhou, Y. The "growth drag" of resources and environment on Nanjing's economic development. China Popul. Resour. Environ. 2011, 21, 558-561.

40. Liu, Y. Economic growth drag in the Central China: Evidence from a panel analysis. Appl. Econ. 2013, 45, 2163-2174. [CrossRef] 
41. Tian, X.; Geng, Y.; Viglia, S.; Bleischwitz, R.; Buonocore, E.; Ulgiati, S. Regional disparities in the Chinese economy. An emergy evaluation of provincial international trade. Resour. Conserv. Recycl. 2017, 126, 1-11. [CrossRef]

42. Song, M.; Ma, X.; Shang, Y.; Zhao, X. Influences of land resource assets on economic growth and fluctuation in China. Resour. Policy 2020, 68, 101779. [CrossRef]

43. Wang, S.; Li, R. Toward the coordinated sustainable development of urban water resource use and economic growth: An empirical analysis of Tianjin City, China. Sustainability 2018, 10, 1323. [CrossRef]

44. Ma, L.; Long, H.; Chen, K.; Tu, S.; LZhang, Y.; Liao, L. Green growth efficiency of Chinese cities and its spatio-temporal pattern. Resour. Conserv. Recycl. 2019, 146, 441-451. [CrossRef]

45. Zhang, Y.; Long, H.; Ma, L.; Tu, S.; Liao, L.; Chen, K.; Xu, Z. How does the community resilience of urban village response to the government-led redevelopment? A case study of Tangjialing village in Beijing. Cities 2019, 95, 102396. [CrossRef]

46. Long, H.; Qu, Y.; Tu, S.; Zhang, Y.; Jiang, Y. Development of land use transitions research in China. J. Geogr. Sci. 2020, 30, 1195-1214. [CrossRef]

47. Gao, X.; Su, L.; Liu, Y. Optimal Allocation of Construction Land Based on GIS. In Proceedings of the 2009 First International Workshop on Database Technology and Applications, Wuhan, China, 25-26 April 2009.

48. Liu, Y.; Luo, T.; Liu, Z.; Kong, X.; Li, J.; Tan, R. A comparative analysis of urban and rural construction land use change and driving forces: Implications for urban-rural coordination development in Wuhan, Central China. Habitat Int. 2015, 47, 113-125. [CrossRef]

49. Zhang, Y.; Long, H.; Tu, S.; Ge, D.; Ma, L.; Wang, L. Spatial identification of land use functions and their tradeoffs/synergies in China: Implications for sustainable land management. Ecol. Indic. 2019, 107, 105550. [CrossRef]

50. Song, X.; Huang, Y.; Wu, Z.; Ouyang, Z. Does cultivated land function transition occur in China? J. Geogr. Sci. 2015, 25, 817-835. [CrossRef]

51. Long, H.; Ge, D.; Zhang, Y.; Tu, S.; Qu, Y.; Ma, L. Changing man-land interrelations in China's farming area under urbanization and its implications for food security. J. Environ. Manag. 2018, 209, 440-451. [CrossRef]

52. Qu, Y.; Jiang, G.; Li, Z.; Tian, Y.; Wei, S. Understanding rural land use transition and regional consolidation implications in China. Land Use Policy 2019, 82, 742-753. [CrossRef]

53. Long, H.; Zhang, Y.; Tu, S. Rural vitalization in China: A perspective of land consolidation. J. Geogr. Sci. 2019, 29, 517-530. [CrossRef]

54. Lambin, E.F.; Meyfroidt, P.; Rueda, X.; Blackman, A.; Börner, J.; Cerutti, P.O.; Dietsch, T.; Jungmann, L.; Lamarque, P.; Lister, J.; et al. Effectiveness and synergies of policy instruments for land use governance in tropical regions. Glob. Environ. Chang. 2014, 28, 129-140. [CrossRef]

55. Lu, X.; Shi, Y.; Chen, C.; Yu, M. Monitoring cropland transition and its impact on ecosystem services value in developed regions of China: A case study of Jiangsu Province. Land Use Policy 2017, 69, 25-40. [CrossRef]

56. Lambin, E.F.; Meyfroidt, P. Land use transitions: Socio-ecological feedback versus socio-economic change. Land Use Policy 2010, 27, 108-118. [CrossRef]

57. Meyfroidt, P. Trade-offs between environment and livelihoods: Bridging the global land use and food security discussions. Glob. Food Secur. 2018, 16, 9-16. [CrossRef]

58. Li, Y.; Fan, P.; Liu, Y. What makes better village development in traditional agricultural areas of China? Evidence from long-term observation of typical villages. Habitat Int. 2019, 83, 111-124. [CrossRef]

59. Liu, Y.; Zhou, G.; Liu, D.; Yu, H.; Zhu, L.; Zhang, J. The interaction of population, industry and land in process of urbanization in China: A case study in Jilin Province. Chin. Geogr. Sci. 2018, 28, 529-542. [CrossRef]

60. Ma, L.; Long, H.; Tu, S.; Zhang, Y.; Zheng, Y. Farmland transition in China and its policy implications. Land Use Policy 2020, 92, 104470. [CrossRef]

61. Bruggeman, D.; Meyfroidt, P.; Lambin, E.F. Forest cover changes in Bhutan: Revisiting the forest transition. Appl. Geogr. 2016, 67, 49-66. [CrossRef]

62. Ge, D.; Long, H.; Zhang, Y.; Ma, L.; Li, T. Farmland transition and its influences on grain production in China. Land Use Policy 2018, 70, 94-105. [CrossRef]

63. Li, Y.; Westlund, H.; Liu, Y. Why some rural areas decline while some others not: An overview of rural evolution in the world. J. Rural Stud. 2019, 68, 135-143. [CrossRef]

64. Ma, L.; Long, H.; Tang, L.; Tu, S.; Zhang, Y.; Qu, Y. Analysis of the spatial variations of determinants of agricultural production efficiency in China. Comput. Electron. Agric. 2021, 180, 105890. [CrossRef]

65. Zhang, Y.; Long, H.; Li, Y.; Ge, D.; Tu, S. How does off-farm work affect chemical fertilizer application? Evidence from China's mountainous and plain areas. Land Use Policy 2020, 99, 104848. [CrossRef]

66. Yang, Y.; Wu, C.; Luo, G.; Wei, S. Effects of soil and water resources on economic growth damping in China. Econ. Geogr. 2007, 27, 529-532.

67. Long, H.; Qu, Y. Land use transitions and land management: A mutual feedback perspective. Land Use Policy 2018, 74, 111-120. [CrossRef]

68. Ye, Y. Calculation and analysis of total factor productivity in China and provinces. Economists 2002, 3, 115-121.

69. Wang, X.; Fan, G. The Sustainability of China's Economic Growth-A Cross-century Review and Prospect; Economic Science Press: Beijing, China, 2000. 
70. Ke, S.; Xiang, J. Estimation of the fixed capital stocks in Chinese cities for 1996-2009. Stat. Res. 2012, 29, 19-24.

71. Marshall, R.; Mariam, C. Measurement of Capital Stocks, Consumption of Fixed Capital, and Capital Services; Central American Ad Hoc Group on National Accounts: Santo Domingo, Dominican Republic, 2005.

72. Jantzen, R.T.; Volpert, K. On the mathematics of income inequality: Splitting the gini index in two. Am. Math. Mon. 2012, 119, 824-837. [CrossRef]

73. Lin, F. Economic Statistical Analysis Methods; Social Sciences Academic Press: Beijing, China, 2003; pp. 57-69.

74. Filippini, R.; Mazzocchi, C.; Corsi, S. The contribution of Urban Food Policies toward food security in developing and developed countries: A network analysis approach. Sustain. Cities Soc. 2019, 47, 101506. [CrossRef]

75. Lu, D.D. New factors and new patterns of regional development in China. Geogr. Res. 2003, 22, $261-271$.

76. Li, H.; Xiong, Z.; Xie, Y. Resource tax reform and economic structure transition of resource-based economies. Resour. Conserv. Recycl. 2018, 136, 389-398. [CrossRef] 